\title{
Effect of Adjuvant Chemotherapy on Elderly Stage II High- Risk Colorectal Cancer Patients
}

\author{
Yujin Lee, Inseok Park, Hyunjin Cho, Geumhee Gwak, Keunho Yang, Byung-Noe Bae \\ Department of General Surgery, Inje University Sanggye Paik Hospital, Inje University College of Medicine, Seoul, Korea
}

Purpose: Adjuvant chemotherapy (AC) is recommended for patients with stage II colorectal cancer with adverse features. However, the effect of adjuvant treatment in elderly patients with high-risk stage II colorectal cancer remains controversial. This study aimed to investigate the oncologic outcomes in elderly high-risk stage II colorectal cancer patients who underwent curative resection with or without AC.

Methods: Patients aged over 70 years having stage II colorectal adenocarcinoma with at least 1 adverse feature who underwent radical surgery between 2008 and 2017 at a single center were included. We compared recurrence-free survival (RFS) and overall survival (OS) between patients who received more than $80 \%$ of the planned AC cycle (the AC+ group) and those who did not receive it (the AC- group).

Results: The AC+ and AC- group contained 46 patients and 50 patients, respectively. The log-rank test revealed no significant intergroup differences in RFS $(\mathrm{P}=0.083)$ and $\mathrm{OS}(\mathrm{P}=0.122)$. In the subgroup of 27 patients with more than 2 adverse features, the AC+ group $(n=16)$ showed better RFS $(P=0.006)$ and $O S(P=0.025)$ than the AC- group. In this subgroup, AC was the only significant factor affecting RFS in the multivariate analysis $(\mathrm{P}=0.023)$. AC was significantly associated with OS $(\mathrm{P}=0.033)$ in the univariate analysis, but not in the multivariate analysis $(\mathrm{P}=0.332)$.

Conclusion: Among elderly patients with stage II high-risk colorectal cancer, the AC+ group did not show better RFS or OS than the AC- group. However, selected patients with more than 2 adverse features might benefit from AC.

\section{Keywords: Adjuvant chemotherapy; Aged; Colonic neoplasms; Risk factors; Survival analysis}

\section{INTRODUCTION}

Although the benefit of adjuvant chemotherapy (AC) in stage II colorectal cancer remains controversial, guidelines recommend AC for patients having T4N0/T3N0 cancer with adverse features such as T4 tumor, insufficient nodal harvest, obstruction, or perforation $[1,2]$. Some studies have reported an association among high-risk features, adjuvant treatment, and cancer survival $[3,4]$. However, these studies did not focus on elderly patients despite the steady increase in the number of patients diagnosed with

Received: Sep 22, 2020 - Revised: Apr 26, 2021 - Accepted: May 7, 2021 Correspondence to: Byung-Noe Bae, M.D., Ph.D.

Department of General Surgery, Inje University Sanggye Paik Hospital, 1342 Dongil-ro, Nowon-gu, Seoul 01757, Korea

Tel: +82-2-950-1017, Fax: +82-2-950-1429

E-mail: bnbae@paik.ac.kr

ORCID: https://orcid.org/0000-0002-5542-5626

(C) 2021 The Korean Society of Coloproctology

This is an open-access article distributed under the terms of the Creative Commons Attribution NonCommercial License (https://creativecommons.org/licenses/by-nc/4.0) which permits unrestricted noncommercial use, distribution, and reproduction in any medium, provided the original work is properly cited. colorectal cancer who were aged over 70 years. Moreover, the proportion of elderly patients receiving chemotherapy tends to be lower than that of younger patients [5]. Therefore, the effectiveness of adjuvant therapy in patients with high-risk stage II colon cancer has not been well studied. The present study aimed to investigate the oncologic outcomes in elderly high-risk stage II colorectal cancer patients who underwent curative resection with or without postoperative AC.

\section{METHODS}

\section{Subjects}

Patients over 70 years of age who were diagnosed with T3 or T4 node-negative colorectal adenocarcinoma with at least 1 adverse feature after radical surgery at Inje University Sanggye Paik Hospital in Seoul, Korea between 2008 and 2017 were included in this retrospective study. Patients with distant metastasis, emergent surgery, recurrent cancer, history of neoadjuvant treatment, other synchronous cancer diagnosed within 5 years from the date of surgery, or follow-up duration of less than 6 months were ex- 
cluded. We divided the patients into 2 groups; patients who received over $80 \%$ of the planned $\mathrm{AC}$ cycle (the $\mathrm{AC}+$ group) and those who did not receive it (the AC- group). The present study was approved by the Institutional Review Board of Inje University Sanggye Paik Hospital (No. SGPAIK 2020-03-008) and informed consent was waived.

\section{Data collection}

We collected preoperative clinical data including age, sex, body mass index, American Society of Anesthesiologists physical status classification, Charlson comorbidity index (CCI) score, preoperative carcinoembryonic antigen level, and presence of obstruction. Pathologic variables such as tumor location, histological grade, $\mathrm{T}$ stage, number of retrieved lymph nodes, margin status, lymphatic invasion, venous invasion, perineural invasion, and perforation

Table 1. Patient characteristics

\begin{tabular}{|c|c|c|c|c|}
\hline \multirow{2}{*}{ Variable } & \multirow{2}{*}{ Total } & \multicolumn{2}{|c|}{ Adjuvant chemotherapy ${ }^{a}$} & \multirow{2}{*}{ P-value } \\
\hline & & No & Yes & \\
\hline Patient & $96(100)$ & $50(52.1)$ & $46(47.9)$ & \\
\hline Age (yr) & $77.2 \pm 4.9$ & $78.9 \pm 5.4$ & $75.4 \pm 3.4$ & $0.001^{*}$ \\
\hline Sex & & & & 0.213 \\
\hline Female & $38(39.6)$ & $23(46.0)$ & $15(32.6)$ & \\
\hline Male & $58(60.4)$ & $27(54.0)$ & $31(67.4)$ & \\
\hline Body mass index $\left(\mathrm{kg} / \mathrm{m}^{2}\right)$ & $23.0 \pm 3.1$ & $22.9 \pm 3.3$ & $23.2 \pm 2.8$ & 0.556 \\
\hline Charlson comorbidity index & & & & $0.024^{*}$ \\
\hline 4 & $55(57.3)$ & $23(46.0)$ & $32(69.6)$ & \\
\hline $5-6$ & $41(42.7)$ & $27(54.0)$ & $14(30.4)$ & \\
\hline ASA PS classification & & & & 0.835 \\
\hline$\|$ & $58(60.4)$ & $31(62.0)$ & 27 (58.7) & \\
\hline III & $38(39.6)$ & $19(38.0)$ & $19(41.3)$ & \\
\hline Pathologic grading & & & & 0.369 \\
\hline Well differentiated & $4(4.2)$ & $3(6.0)$ & $1(2.2)$ & \\
\hline Moderately differentiated & $79(82.3)$ & $38(76.0)$ & $41(89.1)$ & \\
\hline Poorly differentiated & $8(8.3)$ & $6(12.0)$ & $2(4.3)$ & \\
\hline Mucinous & $5(5.2)$ & $3(6.0)$ & $2(4.3)$ & \\
\hline pT stage & & & & 0.331 \\
\hline pT3 & $74(77.1)$ & $41(82.0)$ & $33(71.7)$ & \\
\hline pT4 & $22(22.9)$ & $9(18.0)$ & $13(28.3)$ & \\
\hline Tumor location & & & & $>0.999$ \\
\hline Right & $41(42.7)$ & $21(42.0)$ & 20 (43.5) & \\
\hline Left & $55(57.3)$ & $29(58.0)$ & $26(56.5)$ & \\
\hline Margin $<5 \mathrm{~mm}$ & & & & 0.557 \\
\hline No & 83 (86.5) & $42(84.0)$ & 41 (89.1) & \\
\hline Yes & $13(13.5)$ & $8(16.0)$ & $5(10.9)$ & \\
\hline
\end{tabular}

(Continued to the next) were evaluated. Cancers from the caecum to the splenic flexure were defined as right-sided cancers, while those from the descending colon to the rectum were defined as left-sided cancers.

An adverse feature was defined as a poor histologic grade, T4 stage, close margin, less than 12 harvested lymph nodes, lymphatic invasion, venous invasion, perineural invasion, obstruction, or perforation according to the National Comprehensive Cancer Network guidelines [1]. Close margin was defined as a resection margin of less than $5 \mathrm{~mm}$.

Survival data were obtained from the National Cancer Center in Goyang, Korea. Recurrence-free survival (RFS) was calculated from the date of surgery to the date of the first diagnosis of recurrence. Overall survival (OS) was calculated from the date of surgery to the date of death from any cause.

Table 1. Continued

\begin{tabular}{|c|c|c|c|c|}
\hline \multirow{2}{*}{ Variable } & \multirow{2}{*}{ Total } & \multicolumn{2}{|c|}{ Adjuvant chemotherapy $^{a}$} & \multirow{2}{*}{ P-value } \\
\hline & & No & Yes & \\
\hline No. of lymph nodes retrieved & & & & 0.543 \\
\hline$<12$ & $84(87.5)$ & $45(90.0)$ & $39(84.8)$ & \\
\hline$\geq 12$ & $12(12.5)$ & $5(10.0)$ & $7(15.2)$ & \\
\hline Lymphatic invasion & & & & 0.822 \\
\hline No & $26(27.1)$ & $13(26.0)$ & $13(28.3)$ & \\
\hline Yes & 70 (72.9) & $37(74.0)$ & $33(71.7)$ & \\
\hline Venous invasion & & & & 0.107 \\
\hline No & $72(75.0)$ & $41(82.0)$ & $31(67.4)$ & \\
\hline Yes & $24(25.0)$ & $9(18.0)$ & $15(32.6)$ & \\
\hline Perineural invasion & & & & 0.528 \\
\hline No & 85 (88.5) & $43(86.0)$ & $42(91.3)$ & \\
\hline Yes & $11(11.5)$ & $7(14.0)$ & $4(8.7)$ & \\
\hline Obstruction & & & & 0.058 \\
\hline No & $72(75.0)$ & $42(84.0)$ & $30(65.2)$ & \\
\hline Yes & $24(25.0)$ & $8(16.0)$ & $16(34.8)$ & \\
\hline Perforation & & & & 0.606 \\
\hline No & 93 (96.9) & $49(98.0)$ & $44(95.7)$ & \\
\hline Yes & $3(3.1)$ & $1(2.0)$ & $2(4.3)$ & \\
\hline $\begin{array}{l}\text { Preoperative serum CEA } \\
\text { level (ng/mL) }\end{array}$ & $12.7 \pm 58.1$ & $7.8 \pm 21.6$ & $17.5 \pm 79.5$ & 0.858 \\
\hline No. of adverse features & & & & 0.181 \\
\hline $1-2$ & 69 (71.9) & $39(78.0)$ & $30(65.2)$ & \\
\hline $3-5$ & $27(28.1)$ & $11(22.0)$ & $16(34.8)$ & \\
\hline
\end{tabular}

Values are presented as number (\%) or mean \pm standard deviation. ASA, American Society of Anesthesiologists; PS, physical status; pT stage, pathologic T stage; CEA, carcinoembryonic antigen.

aDefined as completion of more than $80 \%$ of the planned adjuvant chemotherapy cycle.

${ }^{*} \mathrm{P}<0.05$. 


\section{Statistical analysis}

All statistical analyses were performed using IBM SPSS Statistics ver. 25.0 (IBM Corp., Armonk, NY, USA). A P-value of $<0.05$ was considered statistically significant. Analysis of associations between categorical variables was performed using the Pearson chi-square test. Continuous variables were compared using the Mann-Whitney U-test. The Kaplan-Meier method and the logrank test were used to analyze RFS and OS. Factors affecting survival were evaluated using the Cox proportional hazards model. Variables with the P-values of $<0.15$ in the univariate analysis were included in the multivariate analysis.

\section{RESULTS}

\section{Patient characteristics}

The mean age of 96 patients who fulfilled the inclusion criteria was 77.2 years (range, $70-91$ years). The mean follow-up duration was 3.5 years (range, 3 months to 10.9 years). Clinical characteristics of patients according to AC are listed in Table 1. Forty-six patients were included in the $\mathrm{AC}+$ group and 50 patients were included in the AC- group. The age of patients from the AC+ group was significantly lower than the age of patients from the AC- group (mean age, 75.4 vs. 78.9 years; $\mathrm{P}=0.001$ ). The $\mathrm{AC}+$ group exhibited higher $\mathrm{CCI}$ score than the AC- group $(\mathrm{P}=0.024)$. No patients received preoperative concurrent chemoradiotherapy in both groups. There were no significant differences in other characteristics between the groups (Table 1).

\section{Survival analysis}

Recurrence was detected in 19 patients (19.8\%). Among these, 11 patients were from the AC- group (22\%) and 8 patients were from the AC+ group (17.4\%). Mean RFS duration of the ACgroup was 60.8 months (95\% confidence interval [CI], 50.3-69.6)

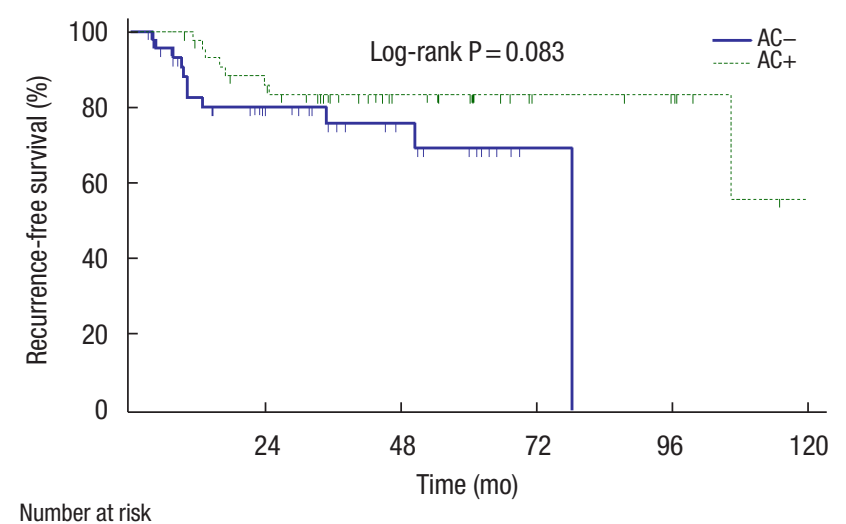

$\begin{array}{lllllllll}\mathrm{AC}- & 50 & 23 & 12 & 2 & 0 & 0 & \\ \mathrm{AC}+ & 46 & 36 & 19 & 8 & 6 & 1 & \text { A }\end{array}$

and mean RFS duration of the AC+ group was 104.8 months (95\% CI, 88.4-121.2) according to the Kaplan-Meier method. However, the log-rank analysis did not show a significant difference in RFS between the groups ( $\mathrm{P}=0.083)$ (Fig. 1A).

Thirty patients died until the date of data collection. Among these, 17 patients (34.0\%) were from the AC- group and $13 \mathrm{pa}-$ tients (28.3\%) were from the AC+ group. Mean OS duration of the AC- group was 75.6 months (95\% CI, 62.2-89.0) and mean OS duration of the AC+ group was 100.0 months (95\% CI, 85.7114.0). The difference between the groups was not statistically significant (log-rank test, $\mathrm{P}=0.122)$ (Fig. 1B).

Factors associated with recurrence-free survival and overall survival (multivariate analysis)

In the univariate analysis using the Cox proportional hazards model, venous invasion, perineural invasion, and the number of adverse features were associated with RFS and OS. In the multivariate analysis, only perineural invasion remained independently associated with RFS (hazard ratio [HR], 4.161; 95\% CI, 1.18814.576; $\mathrm{P}=0.026)$ and OS (HR, 4.760; 95\% CI, 1.713-13.226; $\mathrm{P}=0.003)$. AC was not a significant factor affecting RFS in the univariate analysis $(\mathrm{P}=0.092)$. However the multivariate analysis showed the protective effect of AC (HR, 0.317; 95\% CI, 0.1140.882; $\mathrm{P}=0.028$ ) (Table 2).

\section{Subgroup analysis}

Subgroup analysis of the effect of AC was performed according to the number of adverse features. In the subgroup of 69 patients with fewer than 3 adverse features, no significant difference was observed in RFS $(\mathrm{P}=0.705)$ and $\mathrm{OS}(\mathrm{P}=0.469)$ between the ACgroup $(n=39)$ and the $\mathrm{AC}+$ group $(\mathrm{n}=30)(\mathrm{Fig} .2 \mathrm{~A}, \mathrm{~B})$. However, the AC+ group $(\mathrm{n}=16)$ showed better RFS $(\mathrm{P}=0.006)$ and $\mathrm{OS}$ $(\mathrm{P}=0.025)$ than the $\mathrm{AC}-$ group $(\mathrm{n}=11)$ in the other subgroup of

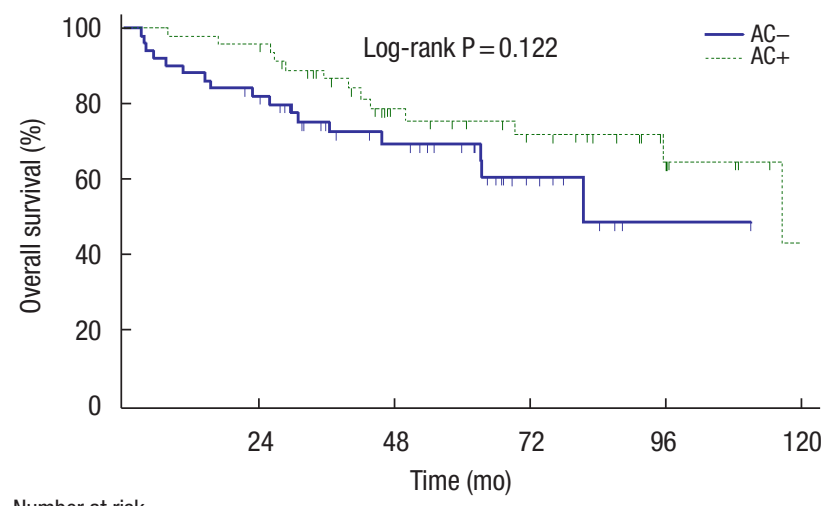

Number at risk

$\begin{array}{llllcll}A C- & 50 & 40 & 23 & 8 & 1 & 0\end{array}$

$\begin{array}{llllrlr}\mathrm{AC}+ & 46 & 44 & 25 & 18 & 9 & 2\end{array}$

Fig. 1. Kaplan-Meier curves showed the effect of adjuvant chemotherapy (AC) on elderly stage II high-risk colorectal cancer patients. (A) Recurrence-free survival. (B) Overall survival. AC+, a group of the patients who received over $80 \%$ of planned AC; AC-, a group of the patients who did not receive AC or received less than $80 \%$ of planned AC. 
27 patients with 3 or more adverse features (Fig. 2C, D).

In the subgroup of patients with 3 or more adverse features, perforation and $\mathrm{AC}$ were associated with RFS in the univariate analysis. AC was the only independent factor affecting RFS in the multivariate analysis (HR, 0.228; 95\% CI, 0.064-0.819; $\mathrm{P}=0.023)$. In the univariate analysis, age and $\mathrm{AC}$ were associated with $\mathrm{OS}$.
However, the multivariate analysis revealed no factors significantly associated with OS (Table 3).

\section{DISCUSSION}

With an increase in the aging population, the number of elderly

Table 2. Univariate and multivariate analysis of recurrent free survival and overall survival

\begin{tabular}{|c|c|c|c|c|c|c|c|c|}
\hline \multirow{3}{*}{ Variable } & \multicolumn{4}{|c|}{ Recurrence-free survival } & \multicolumn{4}{|c|}{ Overall survival } \\
\hline & \multicolumn{2}{|l|}{ Univariate } & \multicolumn{2}{|l|}{ Multivariate } & \multicolumn{2}{|l|}{ Univariate } & \multicolumn{2}{|l|}{ Multivariate } \\
\hline & $\mathrm{HR}(95 \% \mathrm{Cl})$ & P-value & $\mathrm{HR}(95 \% \mathrm{Cl})$ & P-value & $\mathrm{HR}(95 \% \mathrm{Cl})$ & P-value & $\mathrm{HR}(95 \% \mathrm{Cl})$ & P-value \\
\hline Age & $0.996(0.905-1.096)$ & 0.936 & & & 1.001 (0.926-1.082) & 0.979 & & \\
\hline \multicolumn{9}{|l|}{ Sex } \\
\hline Female & 1.000 & & & & 1.000 & & & \\
\hline Male & $0.700(0.283-1.730)$ & 0.440 & & & $1.368(0.640-2.926)$ & 0.419 & & \\
\hline Body mass index & $1.050(0.900-1.225)$ & 0.533 & & & $1.016(0.897-1.151)$ & 0.802 & & \\
\hline \multicolumn{9}{|l|}{$\begin{array}{l}\text { Charlson comorbidity } \\
\text { index }\end{array}$} \\
\hline $3-4$ & 1.000 & & & & 1.000 & & & \\
\hline $5-7$ & $0.833(0.325-2.134)$ & 0.703 & & & $0.912(0.438-1.902)$ & 0.807 & & \\
\hline \multicolumn{9}{|l|}{ Pathologic grading } \\
\hline $\begin{array}{l}\text { Poorly differentiated, } \\
\text { mucinous }\end{array}$ & $1.686(0.483-5.887)$ & 0.413 & & & $1.689(0.643-4.438)$ & 0.288 & & \\
\hline Others & 1.000 & & & & 1.000 & & & \\
\hline \multicolumn{9}{|l|}{ pT stage } \\
\hline pT3 & 1.000 & & & & 1.000 & & & \\
\hline pT4 & $2.579(0.980-6.786)$ & 0.055 & $1.522(0.451-5.134)$ & 0.498 & $0.639(0.290-1.408)$ & 0.267 & & \\
\hline \multicolumn{9}{|l|}{ Tumor location } \\
\hline Right & 1.000 & & & & 1.000 & & & \\
\hline Left & 1.117 (0.439-2.842) & 0.816 & & & $1.030(0.496-2.141)$ & 0.937 & & \\
\hline Margin $<5 \mathrm{~mm}$ & $0.808(0.185-3.540)$ & 0.778 & & & $1.162(0.402-3.359)$ & 0.782 & & \\
\hline $\begin{array}{l}\text { No. of lymph nodes } \\
\text { retrieved }<12\end{array}$ & $1.325(0.407-4.313)$ & 0.640 & & & $1.841(0.767-4.419)$ & 0.172 & & \\
\hline Lymphatic invasion & $3.587(0.805-15.983)$ & 0.094 & $1.949(0.360-10.549)$ & 0.439 & $1.462(0.588-3.634)$ & 0.414 & & \\
\hline Venous invasion & $2.550(1.034-6.289)$ & $0.042^{*}$ & $0.859(0.223-3.304)$ & 0.825 & $2.739(1.335-5.620)$ & $0.006^{*}$ & $2.313(0.833-6.427)$ & 0.108 \\
\hline Perineural invasion & $6.467(2.215-18.884)$ & $0.001^{*}$ & $4.161(1.188-14.576)$ & $0.026^{\star}$ & $6.807(2.821-16.427)$ & $<0.001^{*}$ & $4.760(1.713-13.226)$ & $0.003^{*}$ \\
\hline Obstruction & $0.680(0.225-2.052)$ & 0.494 & & & $0.693(0.283-1.699)$ & 0.423 & & \\
\hline Perforation & $1.594(0.208-12.195)$ & 0.653 & & & $0.046(0.000-89.667)$ & 0.425 & & \\
\hline $\begin{array}{l}\text { Preoperative serum } \\
\text { CEA level }\end{array}$ & $0.997(0.978-1.017)$ & 0.759 & & & $0.996(0.980-1.012)$ & 0.593 & & \\
\hline \multicolumn{9}{|l|}{ No. of adverse features } \\
\hline $1-2$ & 1.000 & & & & 1.000 & & & \\
\hline $3-5$ & $4.627(1.818-11.777)$ & $0.001^{*}$ & $3.305(0.799-13.671)$ & 0.099 & 2.376 (1.159-4.872) & $0.018^{*}$ & 1.079 (0.360-3.233) & 0.892 \\
\hline Adjuvant chemotherapy ${ }^{a}$ & $0.435(0.165-1.145)$ & 0.092 & $0.317(0.114-0.882)$ & $0.028^{*}$ & $0.555(0.261-1.181)$ & 0.127 & $0.487(0.221-1.071)$ & 0.074 \\
\hline
\end{tabular}

$\mathrm{HR}$, hazard ratio; $\mathrm{Cl}$, confidence interval; pT stage, pathologic T stage; CEA, carcinoembryonic antigen.

aDefined as completion of more than $80 \%$ of the planned adjuvant chemotherapy cycle.

${ }^{*} \mathrm{P}<0.05$. 

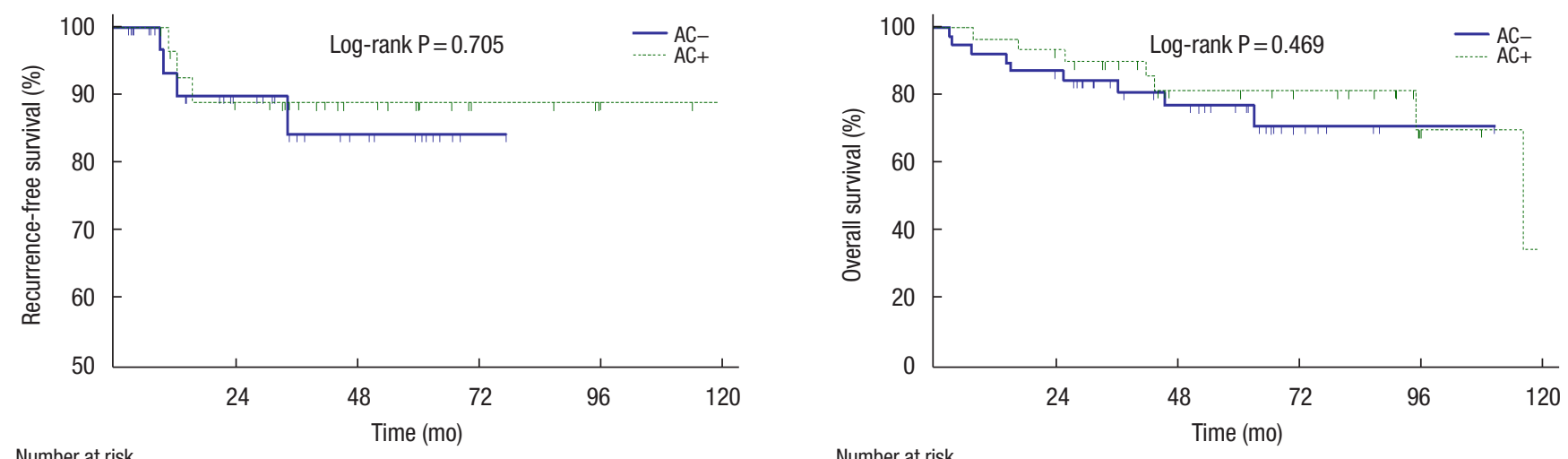

$\begin{array}{lllllll}\mathrm{AC}- & 39 & 20 & 10 & 1 & 0 & 0 \\ \mathrm{AC}+ & 30 & 24 & 14 & 6 & 4 & 1\end{array}$

AC- 39

AC+ $\quad 30$

34

20

6

1
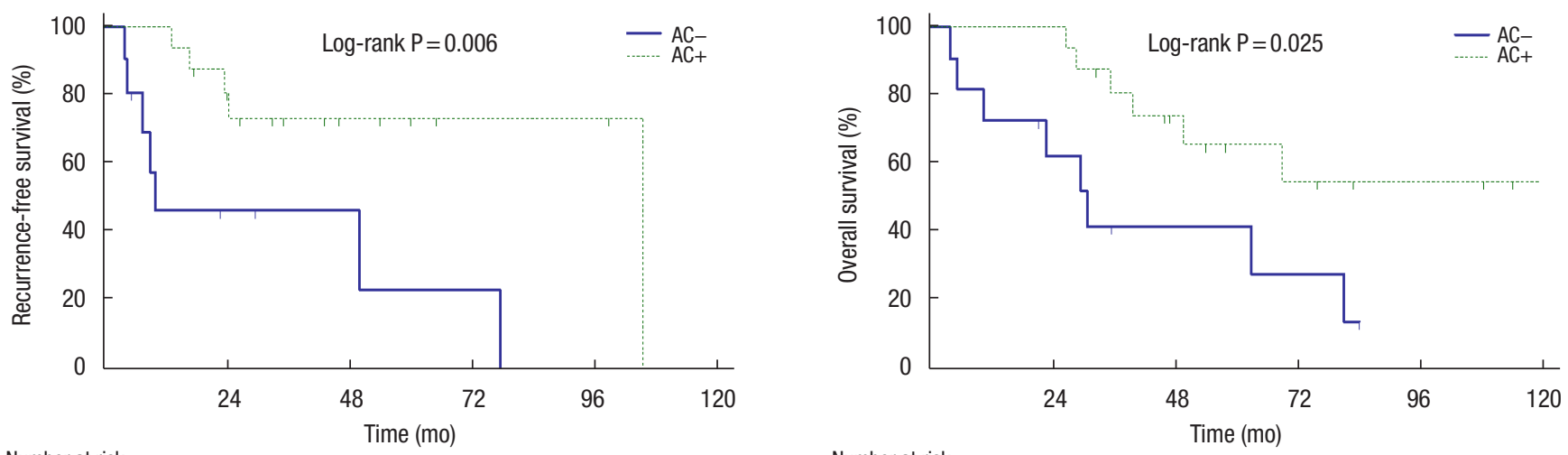

Number at risk

$\begin{array}{lcccccc}\mathrm{AC}- & 11 & 3 & 2 & 1 & 0 & 0 \\ \mathrm{AC}+ & 16 & 12 & 5 & 2 & 2 & 0\end{array}$

0 C

Number at risk

$\begin{array}{ccccccc}\mathrm{AC}- & 11 & 6 & 3 & 2 & 0 & 0 \\ \mathrm{AC}+ & 16 & 16 & 9 & 5 & 3 & 1\end{array}$

Fig. 2. Kaplan-Meier curves showed the effect of adjuvant chemotherapy (AC) on elderly stage II high-risk colorectal cancer patients according to the number of adverse features. (A) Recurrence-free survival of the patients with 1 or 2 adverse features. (B) Overall survival of the patients with 1 or 2 adverse features. (C) Recurrence-free survival of the patients with 3 or more adverse features. (D) Overall survival of the patients with 3 or more adverse features.

colorectal cancer patients has increased. It has been suggested that these patients should not be excluded from adequate treatment including surgery and chemotherapy simply because of their age [6]. However, recent studies regarding the management of colon cancer in the elderly reported that patients at an advanced age were less likely to receive AC [7, 8]. Li et al. [9] evaluated the main reasons for declined chemotherapy through a chart review and telephone questionnaire of 386 stage III colorectal cancer patients aged over 70 years. These reasons included uncertainty in the benefit of chemotherapy, patients' trust in traditional Chinese medicine, economic difficulty, disease information concealed by family members, lack of family support, and poor physical condition after surgery. The lack of evidence regarding the effectiveness of AC in elderly patients prevents doctors from strongly recommending treatment to patients.

Several studies have investigated the effects of AC on elderly pa- tients with stage II colorectal cancer, and the results were inconsistent. In some studies, AC did not show any improvement in disease-free survival or OS in patients with stage II colon cancer who were aged over 70 years [10-12]. In contrast, Kim et al. [13] analyzed the Korean national data and concluded that AC was associated with better OS in elderly stage II colon cancer patients. Their study had a larger number of subjects than the studies that did not demonstrate the effectiveness of AC. The authors also performed a subgroup analysis according to the presence of highrisk features, and the benefits of $\mathrm{AC}$ were found to be consistent in both low-risk and high-risk groups. The propensity matching analysis by Lee et al. [12] showed that high-risk stage II colon cancer did not benefit from AC in the elderly population. However, differences in the dosage and the cycle of $\mathrm{AC}$ were not considered in their study. The present study could not demonstrate better survival in the AC+ group, which may be due to the relatively 
Table 3. Subgroup analysis of recurrent free survival and overall survival in the patients with 3 or more adverse features $(n=27)$

\begin{tabular}{|c|c|c|c|c|c|c|c|c|}
\hline \multirow{3}{*}{ Variable } & \multicolumn{4}{|c|}{ Recurrence-free survival } & \multicolumn{4}{|c|}{ Overall survival } \\
\hline & \multicolumn{2}{|l|}{ Univariate } & \multicolumn{2}{|l|}{ Multivariate } & \multicolumn{2}{|l|}{ Univariate } & \multicolumn{2}{|l|}{ Multivariate } \\
\hline & $\mathrm{HR}(95 \% \mathrm{Cl})$ & P-value & $\mathrm{HR}(95 \% \mathrm{Cl})$ & P-value & $\mathrm{HR}(95 \% \mathrm{Cl})$ & P-value & $\mathrm{HR}(95 \% \mathrm{Cl})$ & P-value \\
\hline Age & $1.003(0.868-1.160)$ & 0.964 & & & $1.125(1.010-1.254)$ & $0.032^{*}$ & $1.088(0.980-1.208)$ & 0.113 \\
\hline \multicolumn{9}{|l|}{ Sex } \\
\hline Female & 1 & & & & 1 & & & \\
\hline Male & $0.412(0.118-1.438)$ & 0.165 & & & $1.075(0.357-3.238)$ & 0.898 & & \\
\hline Body mass index & $1.072(0.865-1.328)$ & 0.526 & & & $1.228(0.988-1.525)$ & 0.064 & $1.194(0.944-1.512)$ & 0.139 \\
\hline \multicolumn{9}{|l|}{$\begin{array}{l}\text { Charlson comorbidity } \\
\text { index }\end{array}$} \\
\hline $3-4$ & 1 & & & & 1 & & & \\
\hline $5-7$ & $0.534(0.115-2.476)$ & 0.423 & & & $1.881(0.625-5.667)$ & 0.261 & & \\
\hline \multicolumn{9}{|l|}{ Pathologic grading } \\
\hline $\begin{array}{l}\text { Poorly differentiated, } \\
\text { mucinous }\end{array}$ & $2.751(0.576-13.147)$ & 0.205 & & & $1.876(0.411-8.559)$ & 0.417 & & \\
\hline Others & 1 & & & & 1 & & & \\
\hline \multicolumn{9}{|l|}{ pT stage } \\
\hline pT3 & 1 & & & & 1 & & & \\
\hline pT4 & $1.905(0.490-7.409)$ & 0.352 & & & $0.936(0.320-2.736)$ & 0.903 & & \\
\hline \multicolumn{9}{|l|}{ Tumor location } \\
\hline Right & 1 & & & & 1 & & & \\
\hline Left & $1.568(0.455-5.406)$ & 0.476 & & & $1.251(0.431-3.626)$ & 0.680 & & \\
\hline Margin $<5 \mathrm{~mm}$ & $0.668(0.141-3.166)$ & 0.611 & & & $1.137(0.354-3.654)$ & 0.830 & & \\
\hline $\begin{array}{l}\text { No. of lymph nodes } \\
\text { retrieved }<12\end{array}$ & $0.708(0.181-2.768)$ & 0.620 & & & 1.615 (0.539-4.839) & 0.392 & & \\
\hline Lymphatic invasion & $\begin{array}{c}21.784 \\
(0.000-13,101,349.717)\end{array}$ & 0.650 & & & $\begin{array}{c}21.874 \\
(0.000-3,231,279.450)\end{array}$ & 0.611 & & \\
\hline Venous invasion & $0.666(0.187-2.370)$ & 0.531 & & & $0.833(0.279-2.493)$ & 0.744 & & \\
\hline Perineural invasion & 2.019 (0.498-8.189) & 0.325 & & & $2.231(0.634-7.854)$ & 0.211 & & \\
\hline Obstruction & $0.619(0.162-2.364)$ & 0.483 & & & $0.501(0.139-1.804)$ & 0.291 & & \\
\hline Perforation & $24.980(1.562-399.590)$ & $0.023^{*}$ & 12.611 (0.768-207.113) & 0.076 & $0.043(0.000-424.262)$ & 0.503 & & \\
\hline $\begin{array}{l}\text { Preoperative serum CEA } \\
\text { level }(\mathrm{ng} / \mathrm{mL})\end{array}$ & $0.995(0.973-1.018)$ & 0.662 & & & $0.992(0.967-1.018)$ & 0.563 & & \\
\hline $\begin{array}{l}\text { Adjuvant } \\
\text { chemotherapy }^{\mathrm{a}}\end{array}$ & $0.207(0.060-0.717)$ & $0.013^{*}$ & $0.228(0.064-0.819)$ & $0.023^{*}$ & $0.313(0.107-0.910)$ & $0.033^{*}$ & $0.535(0.151-1.891)$ & 0.332 \\
\hline
\end{tabular}

$\mathrm{HR}$, hazard ratio; $\mathrm{Cl}$, confidence interval; pT stage, pathologic T stage; CEA, carcinoembryonic antigen.

aDefined as completion of more than $80 \%$ of the planned adjuvant chemotherapy cycle.

${ }^{*} \mathrm{P}<0.05$.

small number of study subjects.

Some studies have shown a relationship between the number of risk factors and survival in stage II high-risk colorectal cancer patients. These studies have suggested the need for AC in patients with multiple risk factors $[3,13,14]$. However, Peng et al. [4] reported that AC did not show a significant improvement in cancerspecific survival in the stage II high-risk group with 2 or more adverse features. In the present study, the response to AC depended on the number of adverse features. The $\mathrm{AC}+$ group with 3 or more adverse features showed better RFS and OS than the ACgroup with 3 or more adverse features. The difference between the present study and the study by Peng et al. [4] was that the present study was limited to patients over 70 years of age and was based on 3 or more risk factors. However, the number of subjects was small. The proportion of the $\mathrm{AC}+$ group was higher in patients with lower CCI; however, the difference was not statistically significant. AC remained associated with significantly better RFS in the subgroup with 3 or more adverse features and lower CCI. 
The number of patients with 3 or more adverse features and high CCI was too small to be analyzed.

A previous study concluded that each risk factor had a different degree of impact on survival [3]. In that study, only T4 cancers and their combination with other risk factors exhibited survival benefit after AC. Sixteen out of 22 patients with 3 or more adverse features had T4 tumors in our study. However, the number of subjects was not sufficient for comparison. In addition to the effects of the number of adverse features, more research regarding the effects of different types of adverse features is needed.

Recently, several large trials have been conducted to investigate the duration of $\mathrm{AC}$ for colorectal cancer based on concerns regarding oxaliplatin-induced neurotoxicity and the cost of full delivery of AC. According to Formica et al. [15], the overall results suggested the noninferiority and lower toxicity of the 3-month regimen compared to the 6-month regimen despite some limitations. In patients with stage II colorectal cancer, the 3-month therapy was associated with substantially worse survival than the 6-month regimen in one of the trials [16] but did not show worse survival compared to the 6-month regimen in another trial [17]. In the present study, $\mathrm{AC}$ did not show significant differences in RFS and OS between the AC- and the $\mathrm{AC}+$ groups when the $\mathrm{AC}+$ group was defined as patients who completed more than half of the planned cycles. However, when the AC+ group was defined as patients who completed more than $80 \%$ of the planned cycles, the survival of patients in the AC+ group was significantly better than that in patients from the AC- group. However, heterogeneity of the chemotherapy regimen was not taken into account and the number of subjects was relatively insufficient. Thus, further studies are needed to validate these results.

The present study has several limitations. It was a retrospective study conducted at a single center. We did not compare the survival rates associated with various chemotherapy regimens due to an insufficient number of the $\mathrm{AC}+$ groups. In the $\mathrm{AC}+$ group, 16 patients received FOLFOX4 (5-fluorouracil + oxaliplatin) treatment, and 30 received oral chemotherapy such as doxifluridine [7], tegafur/uracil [17], and capecitabine [6]. In addition, cancerspecific survival could not be evaluated, as the National Cancer Center survival data did not include the cause of death. Nevertheless, the present study is one of a few studies focusing on the survival benefits of AC in elderly patients with stage II high-risk colorectal cancer, especially with respect to the number of adverse features.

In conclusion, among the elderly patients with stage II high-risk colorectal cancer, the AC+ group did not show significantly better RFS and OS than the AC- group. However, selected patients with 3 or more adverse features might benefit from AC.

\section{CONFLICT OF INTEREST}

No potential conflict of interest relevant to this article was reported.

\section{REFERENCES}

1. National Comprehensive Cancer Network (NCCN). NCCN guidelines for patients colon cancer 2021 [Internet]. Goyang: NCCN; c2021 [cited 2020 Sep 22]. Available from: https://www. nccn.org/patients/guidelines/content/PDF/colon-patient.pdf.

2. Costas-Chavarri A, Nandakumar G, Temin S, Lopes G, Cervantes A, Cruz Correa M, et al. Treatment of patients with early-stage colorectal cancer: ASCO resource-stratified guideline. J Glob Oncol 2019;5:1-19.

3. Babcock BD, Aljehani MA, Jabo B, Choi AH, Morgan JW, Selleck MJ, et al. High-risk stage II colon cancer: not all risks are created equal. Ann Surg Oncol 2018;25:1980-5.

4. Peng SL, Thomas M, Ruszkiewicz A, Hunter A, Lawrence M, Moore J. Conventional adverse features do not predict response to adjuvant chemotherapy in stage II colon cancer. ANZ J Surg 2014;84:837-41.

5. Bojer AS, Roikjær O. Elderly patients with colorectal cancer are oncologically undertreated. Eur J Surg Oncol 2015;41:421-5.

6. Kim JH. Chemotherapy for colorectal cancer in the elderly. World J Gastroenterol 2015;21:5158-66.

7. Kim GM, Ahn JB, Rha SY, Kim HS, Kang B, Kim MW, et al. Changing treatment patterns in elderly patients with resectable colon cancer. Asia Pac J Clin Oncol 2013;9:265-72.

8. Merchant SJ, Nanji S, Brennan K, Karim S, Patel SV, Biagi JJ, et al. Management of stage III colon cancer in the elderly: practice patterns and outcomes in the general population. Cancer 2017;123: 2840-9.

9. Li P, Li F, Fang Y, Wan D, Pan Z, Chen G, et al. Efficacy, compliance and reasons for refusal of postoperative chemotherapy for elderly patients with colorectal cancer: a retrospective chart review and telephone patient questionnaire. PLoS One 2013;8: e55494.

10. McCleary NJ, Meyerhardt JA, Green E, Yothers G, de Gramont A, Van Cutsem E, et al. Impact of age on the efficacy of newer adjuvant therapies in patients with stage II/III colon cancer: findings from the ACCENT database. J Clin Oncol 2013;31:2600-6.

11. Tsai TC, Sun JL, Lin WL, Lee SW, Chang SC, Wu PH, et al. Survival of adjuvant chemotherapy among elderly patients with stage II colon cancer. Int J Gerontol 2018;12:94-9.

12. Lee KY, Park JW, Lee KY, Cho S, Kwon YH, Kim MJ, et al. Adjuvant chemotherapy does not provide survival benefits to elderly patients with stage II colon cancer. Sci Rep 2019;9:11846.

13. Kim MK, Won DD, Park SM, Kim T, Kim SR, Oh ST, et al. Effect of adjuvant chemotherapy on stage ii colon cancer: analysis of Korean national data. Cancer Res Treat 2018;50:1149-63.

14. Gertler R, Rosenberg R, Schuster T, Friess H. Defining a highrisk subgroup with colon cancer stages I and II for possible adjuvant therapy. Eur J Cancer 2009;45:2992-9.

15. Formica V, Zaniboni A, Loupakis F, Roselli M. Noninferiority of three months versus six months of oxaliplatin-based adjuvant chemotherapy for resected colon cancer. How should IDEA find- 
ings affect clinical practice? Int J Cancer 2018;143:2342-50.

16. Sobrero A, Lonardi S, Rosati G, Di Bartolomeo M, Ronzoni M, Pella N, et al. FOLFOX or CAPOX in stage II to III colon cancer: efficacy results of the Italian Three or Six Colon Adjuvant Trial. J Clin Oncol 2018;36:1478-85.
17. Iveson TJ, Kerr RS, Saunders MP, Cassidy J, Hollander NH, Tabernero J, et al. 3 versus 6 months of adjuvant oxaliplatin-fluoropyrimidine combination therapy for colorectal cancer (SCOT): an international, randomised, phase 3, non-inferiority trial. Lancet Oncol 2018;19:562-78. 